\section{References}

1 Drossman DA, Powell DW, Sessions JT. The irritable bowel syndrome. Gastroenterology 1977;73:811-22.

2 Ferguson A, Sircus W, Eastwood MA. Frequency of 'functional' gastrointestinal disorders. Lancet 1977; ii:613-4.

3 Thompson WG, Keaton KW. Functional bowel disorders in apparently healthy people. Gastroenterology 1980;79:283-8.

4 Drossman DA, Sandler RS, McKee DC, et al. Bowel patterns among subjects not seeking health care. Gastroenterology 1982;83:529-34.

5 Fielding JF. The irritable bowel syndrome. Part I. Clinical spectrum. Clinical Gastroenterology 1977;6:607-22

6 Hillman LC, Stace NH, Pomare EW. Irritable bowel patients and their long-term response to a high fiber diet. Am $\mathcal{F}$ Gastroenterol 1984;79:1-7.

7 Esler MD, Goulston KJ. Levels of anxiety in colonic disorders. N Engl f Med 1973;288: 16-20.

8 Palmer RL, Stonehill E, Crisp AH, et al. Psychological characteristics of patients with the irritable bowel syndrome Postgrad Med f 1974:50:416-9.

9 Latimer P, Sarna S, Campbell D, et al. Colonic motor and myoelectrical activity: a comparative study of normal subjects, psychoneurotic patients and patients with irritable bowel syndrome. study of normal subjects, psycho
Gastroenterology 1981;80:893-901.

10 Hislop IG. Psychological significance of the irritable colon. Gut 1971;12:452-7.

11 Liss JL, Alpers DH, Woodruff RA. The irritable colon syndrome and psychiatric illness. Diseases of the Nervous System 1973;34:151-7.

12 Young ST, Alpers DH, Norland CC, et al. Psychiatric illness and the irritable bowel syndrome. Gastroenterology 1976;70:162-6.

13 Welch GW, Stace NH, Pomare EW. Specificity of psychological profiles of irritable bowel syndrome patients. Aust $N Z$ J Med 1984;14:101-4.

14 Boe GP, Ponder LD. Blood donors and non-donors: a review of the research. Am $\mathcal{F}$ Med Technol 1981;47:248-53.

15 Diem K, ed. Documenta Geigy. Scientific tables. 6th ed. St Leonards, New South Wales: Geigy Pharmaceuticals, 1962
16 Lipman RS, Cole JO, Park LC, et al. Sensitivity of symptom and non-symptom-focused criteria outpatient drug efficacy. Am $\}$ Psychiatry 1965;122:24-7.

17 Covi L, Lipman RS, Pattison JH, et al. Length of treatment with anxiolytic-sedatives and response to their sudden withdrawal. Acta Psychiarr Scand 1973;49:51-64.

18 Derogatis LR, Lipman RS, Rickels K. The Hopkins symptom check list. Behav Sci 1974; 19: 1-14

19 Jacobs R, Kafry D, Zedeck S. Expectations of behaviourally anchored rating scales. Personref Psychology 1980;33:595-640.

20 Taylor AJW. Adaption of New Zealand research personnel in the Antarctic. In: OG Edholm EK Gunderson, eds. Polar human biology. London: Heinemann Medical Books, 1973:417-20

21 Whitehead WE, Engel BT, Schuster MM. Irritable bowel syndrome. Physiological ase psychological differences between diarrhoea-predominant and constipation-predominant psychological differences between

22 Wise TN, Cooper JN, Ahmed S. The efficacy of group therapy for patients with irritable boweI We

23 Walkey FH, McCoromick IA Muliple repli . number of factor problems. Multivariate Behavioural Research (in press).

24 Downie NH, Heath RW. Basic statistical methods. 3rd ed. New York: Harper International, 197 25 Hettmansperger TP. Statistical inference based on ranks. New York: J Wiley, 1984.

26 Nathanson CA. Sex illness and medical care: a review of data theory and method. Soc Sci M 1977;11:13-25.

27 Lewis CE, Lewis MA. The potential impact of sexual equality on health. $N$ Engl f M尺 1977;297:863-9.

28 Bernstein B, Kane R. Physicians' attitudes towards female patients. Med Care 1981;19:600-8. C) 29 Hooper EM, Loretto MC, Goodwin JM, et al. Patient characteristics that influence physicißึ behaviour. Med Care 1982;20:630-8.

30 Crown S, Crisp AH. A short clinical diagnostic self-rating scale for psychoneurotic patients. The Middlesex Hospital questionnaire. Brf Psychiatry 1966;112:917-23.

31 Crisp AH, Jones M, Gaynor $P$, et al. The Middlesex Hospital questionnaire. A validity study. $B r$ Med Psychology 1978:51:269-80.

32 Crockett R. A short self-rating scale in the remand setting. Br J Psychiatry 1969;115:1141-50.

(Accepted 7 August 1985)

\title{
Early neurological complications of coronary artery bypass surgery
}

\author{
PAMELA J SHAW, DAVID BATES, NIALL E F CARTLIDGE, DAVID HEAVISIDE, \\ DESMOND G JULIAN, DAVID A SHAW
}

\begin{abstract}
A prospective study of 312 patients undergoing elective coronary artery bypass surgery was undertaken to determine the incidence, severity, and functional impact of postoperative neurological complications. Detailed evaluation of the patients showed that neurological complications after surgery were common, occurring in 191 of the 312 patients (61\%). Although such a high proportion of the total developed detectable changes, serious neurological morbidity was rare. Neurological disorders resulted in death in only one patient $(0.3 \%)$ and severe disability in only four $(1 \cdot 3 \%)$. Forty eight patients were mildly disabled during the early postoperative period, and the remaining 138 with neurological signs had no serious functional disability.

The postoperative neurological disorders detected included one death from cerebral hypoxic damage. Prolonged depression
\end{abstract}

Department of Neurology, University of Newcastle upon Tyne NE2 4HH PAMELA J SHAW, MRCP, research registrar DAVID BATES, FRCP, consultant and senior lecturer

NIALL E F CARTLIDGE, FRCP, consultant and senior lecturer DAVID A SHAW, FRCP, professor

Cardiothoracic Unit, Freeman Hospital, Newcastle upon Tyne DAVID HEAVISIDE, FFARCS, consultant in cardiothoracic anaesthesia

Department of Cardiology, University of Newcastle upon Tyne DESMOND G JULIAN, MD, FRCP, professor

Correspondence to: Dr Pamela J Shaw. of conscious level was observed in 10 patients $(3 \%)$ and definit stroke in $15(5 \%) ; 78(25 \%)$ developed ophthalmological abno\& malities and $123(39 \%)$ primitive reflexes; postoperativ psychosis was observed in four (1\%); and $37(12 \%)$ develope $\mathbf{9}$ disorders of the peripheral nervous system.

The incidence of serious neurological problems such as fata cerebral damage, stroke, and brachial plexopathy is in accord ance with experience elsewhere. Lesser abnormalities, whos detection required detailed neurological examination, were much commoner than expected from previous reports.

\section{Introduction}

Neurological complications of heart surgery have been recognised since the early description by Fox et al in 1954. ${ }^{1}$ Extracorporeat circulation has been implicated as a source of neurological mor bidity in many subsequent studies. ${ }^{2-8}$ The neurological disorders detected have affected all levels of the nervous system. Theifu reported incidence has varied widely, from 0 to $100 \%,{ }^{90}$ depending mainly on the timing of postoperative assessment, the neurologica skill of the assessors, and other differences in study design. ThE incidence of severe neurological complications has undoubtedli decreased owing to improvements in surgical and anaesthetic methods and particularly in extracorporeal circulation equipe ment. ${ }^{112}$ Milder complications have attracted less attention perhaps because they are transient or are less of a threat to life thai the primary cardiac disorder.

Coronary artery bypass surgery using saphenous vein grafts was introduced by Favaloro in $1967 . .^{13}$ This procedure has become increasingly important in the management of patients wit ischaemic heart disease. Compared with patients undergoing othes 
forms of heart surgery those undergoing coronary artery bypass grafting are a group in whom there is likely to be a higher incidence of subclinical or symptomatic cerebrovascular disease. Little information exists on the neurological morbidity associated with coronary artery bypass surgery, previous studies having referred mainly to surgery for congenital or valvular heart disease. In view of the current demand for substantially increased provisions for coronary artery bypass operations $\mathrm{s}^{14}$ it is particularly important that a clear picture of postoperative neurological complications of all grades of severity should be available.

The present prospective study was designed to: $(a)$ define the incidence, magnitude, and clinical course of neurological and neuropsychological abnormalities occurring after coronary artery bypass surgery and $(b)$ identify preoperative, operative, and postoperative factors that may predispose to these complications. The incidence and severity of clinical neurological abnormalities detected during the first seven days after surgery are described. Preliminary findings in the first 100 patients have been reported. ${ }^{15}$

\section{Patients and methods}

The study cohort comprised 312 patients who underwent elective coronary bypass surgery from September 1983 to August 1984 at the regional cardiothoracic centre in Newcastle upon Tyne. The following groups of patients were excluded from the study: those undergoing emergency surgery or requiring intensive care unit surveillance immediately before operation; those scheduled for valve replacement or aneurysm resection in addition to coronary bypass surgery; those admitted less than 24 hours before surgery; and those who did not speak English. Of the patients eligible to participate, $92 \%$ were entered into the study. The cohor included 276 men $(89 \%)$ and 36 women (11\%), with an age range of 33-70 (mean (SD) $53 \cdot 4(7 \cdot 4)$ ).

The anaesthetic regimen used was based on a modified form of neuroleptanalgesia, supplemented by a volatile agent, nitrous oxide, and muscle relaxants. All operations required exposure of the heart through a median sternotomy and cannulation of the ascending aorta and inferior and superior vena cava. After systemic heparinisation cardiopulmonary bypass was instituted with moderate haemodilution and hypothermia $\left(28^{\circ} \mathrm{C}\right)$. Three types of disposable oxygenator were used: Travenol membrane (46\%), Harvey bubble (34\%), and Cobe membrane (20\%). A Stöckert roller pump and cardiotomy reservoirs with integral microaggregate filtration were used. Arterial line filters were not included in the circuit. The system was routinely primed with a balanced electrolyte solution. Cardiac activity was stopped with aortic cross clamping, topical cooling, and infusion of potassium cardioplegic solution into the aortic root. Intracardiac venting was not routinely used. Non-pulsatile perfusion was used in $57 \%$ of operations and pulsatile perfusion in $43 \%$. Clotting time, blood gases, plasma electrolyte concentrations, and packed cell volume were measured regularly throughout the procedure, and arterial, central venous, and pump line pressures were continuously monitored.

All patients were assessed before and after surgery by one investigator (PJS). In the two days before surgery the patients underwent detailed clinical neurological assessment to define preoperative neurological abnormalities and identify previous episodes of neurological illness and possible risk factors for cerebrovascular disease. In addition, a neuropsychological evaluation was made using a battery of 10 standard tests. Postoperatively the patients were seen and neurologically assessed on a daily basis. Repeat psychometric testing was performed on about the seventh day. Postoperative neurological investigations such as computed tomography and electroencephalography were performed when clinically indicated.

\section{Results}

One hundred and nine of the 312 patients $(35 \%)$ had detectable abnormalities on preoperative neurological examination. Minor signs, including peripheral nerve disorders and abnormalities of tendon or primitive reflexes were present in $93(30 \%)$ patients. Eight patients (3\%) had residual signs of stroke or retinal vascular occlusion. In 20 patients $(6 \%)$ ophthalmological abnormalities were observed, including diabetic retinopathy, choroidoretinitis, retinitis pigmentosa, and glaucomatous changes. Rarer findings included Bell's palsy in two patients, Parkinson's disease in three, steroid myopathy in one, signs resulting from a partially resected sphenoidal wing meningioma in one, and an amnestic syndrome resulting from previous heart surgery in one. Such preoperative abnormalities emphasise the importance of prospective evaluation of the patients.

\section{POSTOPERATIVE RESULTS}

Four patients $(1 \%)$ died. Three of the deaths were due to cardiac disorders, and one resulted from extensive brain damage. Of the 312 patients, 191 (61\%) developed new clinical abnormalities after surgery.

Fatal cerebral hypoxic damage occurred in one patient, who became profoundly hypotensive at the end of his operation. He remained in the vegetative state until his death on the 16th postoperative day. Histological examination of the brain showed diffuse cortical neuronal ischaemic change most noticeable in the parietal cortex.

Prolonged depression of conscious level for more than 24 hours after surgery, not attributable to sedative drugs, occurred in 10 patients (3\%). Normal consciousness returned within three days in five patients and within eight days in three. One patient did not become normally alert for 12 days, and another, mentioned above, remained in a vegetative state until death. Five of the 10 patients had a stroke and all eight of those who had repeat psychometric testing showed considerable cognitive impairment. In one patient the development of acute renal failure contributed to the encephalopathy, but in the others no specific metabolic disorders were identified.

Definite stroke occurred in 15 patients $(5 \%)$ : two had hemiparesis and dysphasia; one hemiparesis and cortical blindness; one hemiparesis and hemianopia; one hemiparesis, quadrantanopia, and parietal syndrome; two hemianopia and non-dominant parietal syndrome; one hemianopia and dysphasia; one inferior quadrantanopia; and six cortical hand weakness. In four the stroke caused major functional deficit, but the 11 others were not severely disabled. In 12 of the 15 patients the cerebrovascular accident was discovered immediately on recovery from anaesthesia. The three others developed their stroke postoperatively-within the first 24 hours in two and on the third day after surgery in one. The signs indicated damage of the left hemisphere in seven patients and of the right hemisphere in seven. One patient, who developed a left hemiparesis and cortical blindness, had areas of infarction in both cerebral hemispheres, as shown by computed tomography. Possible minor stroke occurred in a further nine patients (3\%). Two developed reflex asymmetry, one a unilateral intention tremor, and one showed transient unilateral sensory inattention. A further five patients developed isolated extensor plantar responses that were unilateral in two cases and bilateral in three.

Ophthalmological abnormalities were observed in 78 patients (25\%). Areas of retinal infarction, producing the appearance of cotton wool spots, developed in 54 patients $(17 \%)$. The infarcts were bilateral in 20 patients and unilateral in 34 . Twenty five out of $54(46 \%)$ had symptomatic visual disturbance, usually complaining of difficulty in reading or of blurring or haziness of an area of their peripheral vision. In eight patients one or more retinal emboli were observed immediately after operation. In each case the embolus consisted of a yellowish refractile body and was usually lodged at a vascular bifurcation. Four of these patients were asymptomatic and four complained of mild visual impairment. Eight patients (3\%) developed a visual field defect; one of these developed a transient hemianopia lasting less than 24 hours, which has not been included under the heading of stroke.

Fourteen further patients $(5 \%)$ developed reduction of visual acuity of at least two points on the Jaeger reading chart, for which no definite cause was established on clinical examination. This was bilateral in six cases and unilateral in eight.

Primitive reflexes developed in 123 patients (39\%). One hundred and seven (34\%) developed palmomental reflexes, of which 48 were bilateral and 59 unilateral. Thirty six patients (12\%) developed a pout reflex, and one showed bilateral grasp reflexes.

Postoperative psychosis was observed in four patients (1\%). This consisted of a florid paranoid hallucinatory state, which in two of the patients was present immediately after operation and in the other two developed after a lucid interval of three days. Two patients had other associated abnormalities of the central nervous system and all four showed impairment on postoperative psychometric testing. The mental state returned to normal within 48 hours in two patients, but the other two were still mildly disturbed at the time of discharge from hospital.

Peripheral nervous system complications developed in 37 patients (12\%). Twenty one $(7 \%)$ developed brachial plexopathy affecting the C8 and $\mathrm{Tl}$ roots in all cases. One had bilateral lesions and four showed an associated ipsilateral Horner's syndrome. Five patients were incapacitated by severe radicular pain. A further 17 patients developed disorders of other peripheral nerves: seven in the ulnar nerve; five in the lateral femoral cutaneous nerve; two in the median nerve; and one each in the radial, common peroneal, and phrenic nerves.

\section{FUNCTIONAL DISABILITY}

Many of the neurological complications detected did not give rise to significant functional disability. Of the 191 patients with abnormalities, 138 $(72 \%)$ were not seriously disabled during their time in hospital. Forty eight 
had some difficulty in managing normal everyday activities and were considered to be mildly disabled. Four patients were severely incapacitated, to the extent that they would have been incapable of leading an independent existence. One patient died as a result of neurological damage.

In most cases these postoperative neurological abnormalities were still present at discharge from hospital. Resolution of the neurological disorder occurred in only seven patients $(4 \%)$ during their stay in hospital.

\section{Discussion}

The cardiological benefits of coronary artery bypass surgery are well established in terms of both relief of angina ${ }^{16}$ and improved survival in defined subgroups of patients. ${ }^{17}$ Improvements in surgical and anaesthetic methods and cardiopulmonary bypass technology have resulted in a low incidence of major perioperative complications. Nevertheless, neurological complications continue to be a source of postoperative morbidity and mortality. Of the 312 patients in this study, $190(61 \%)$ showed clinically detectable neurological dysfunction after surgery. Many of these neurological abnormalities were asymptomatic or produced only mild disability. We think, however, that their detection and monitoring are important in relation to future refinements in extracorporeal circulation techniques, with the ultimate aim of eliminating neurological hazards in cardiac surgery.

We do not suppose that these findings are peculiar to the cardiothoracic centre in Newcastle, whose operative mortality and incidence of fatal neurological complications in coronary artery bypass surgery compares favourably with those of other major centres. ${ }^{1819}$ The $61 \%$ incidence of clinical neurological complications found in this study seems comparatively high because we have documented neurological abnormalities of all grades of severity and included minor disorders such as primitive reflexes and ophthalmological changes. If we look at the incidence of the more important single abnormalities such as fatal cerebral damage, stroke, and brachial plexopathy we find that our figures are similar to those in a prospective study by the Cleveland clinic group. The incidence of fatal brain damage in this study was one out of 312 $(0 \cdot 3 \%)$. In the study of Breuer et al death with associated severe deficit of the central nervous system occurred in three out of 418 patients $(0 \cdot 7 \%) .{ }^{20}$ Definite stroke occurred in 15 out of $312(4 \cdot 8 \%)$ of our patients compared with $5 \cdot 2 \%$ of Breuer's. ${ }^{21}$ We detected brachial plexus damage in $21(6 \cdot 7 \%)$ patients compared with an incidence of $5.5 \%$ in the Cleveland clinic study. ${ }^{22}$

Several retrospective analyses have shown a low incidence of neurological complications associated with coronary artery bypass surgery. Lee $e t$ al found that $0 \cdot 7 \%$ of 943 patients suffered cerebral infarction during and after surgery ${ }^{23}$ Gonzales-Scarano and Hurtig reported that 19 of 1427 patients $(1 \cdot 3 \%)$ developed postoperative neurological complications. ${ }^{24}$ Martin et al found that eight of 253 patients $(3 \cdot 2 \%)$ developed intraoperative or early postoperative stroke. ${ }^{25}$ In Bojar's retrospective series of 3206 patients 32 developed a major neurological deficit after surgery. ${ }^{26}$ Coffey et al found that $63(3.8 \%)$ of 1669 patients developed altered mental state, stroke, or seizure postoperatively. ${ }^{27}$ Sotaniemi has clearly shown, however, that retrospective evaluation of postoperative neurological complications gives falsely low prevalences when compared with careful prospective neurological assessment. ${ }^{28}$

Most patients with postoperative neurological disorders in this study had routine, uncomplicated operations. It therefore seems likely that many neurological disorders result from hazards inherent in the extracorporeal circulation process, which remains an imperfect replacement for normal functions of the heart and lungs.

Possible aetiological mechanisms for neurological damage during heart surgery using extracorporeal circulation include: (a) macroembolisation resulting, for example, from air in the perfusion circuit ${ }^{29}$ dislodgment of atheromatous debris from the aorta,${ }^{30}$ or release of left ventricular thrombus during cardiac manipulation. ${ }^{31}$ (b) Microembolism of fat, ${ }^{32}$ air, ${ }^{33}$ platelet aggregates, ${ }^{34}$ fibrin,,$^{35}$ or silicone. $^{36}$ (c) Cerebral hypoperfusion due to low flow, ${ }^{37}$ hypotension, ${ }^{38}$ incorrect placement of the cannula, or cerebrovascular occlusive disease. (d) Brachial plexus injury owing to excessive sternal retraction, penetration by a posterior fractured segment of the first rib, or injury during internal jugular vein cannulation. ${ }^{39} 40$ (e) Other peripheral nerve injuries are likely to result from direct trauma during surgery or associated with postoperative care.

This is the first large scale study in which patients undergoing coronary artery bypass surgery have been prospectively assessed by clinical neurological and neuropsychological methods. Details of the neuropsychological complications are reported separately. Our aim was to detect all grades of neurological dysfunction, including transient and subclinical disorders. A high proportion of patients in this study developed primitive reflexes after surgery. The clinical importance of these primitive reflexes is uncertain. They are thought to be due to supranuclear motor system dysfunction and represent "release" phenomena resulting from reduction of cortical inhibition in lower centres. They may be normal phenomena in some of the healthy population but are most commonly seen in patients with diffuse cerebral hemisphere disease or lesions of the frontal lobes. ${ }^{+1}$ We think that their development after cardiopulmonary bypass surgery may well reflect mild cerebral injury. This is supported by the significant association between the development of primitive reflexes and other signs of damage in the central nervous system such as stroke $\left(\chi^{2}=6 \cdot 16, p<0.02\right)$ and depression of consciousness $\left(\chi^{2}=4 \cdot 13, p<0 \cdot 05\right)$.

We emphasise that the data reported here refer to only the early period after operation and that long term follow up is in progress. This will enable us to describe the recovery patterns of these early disorders and determine the prevalence of long term neurological morbidity. It will also establish the impact of early neurological complications on the patient's domestic life and work.

The application of these methods may help answer some of the many unresolved questions about cerebral protection during open heart surgery. The use of membrane $v$ bubble oxygenators, the employment of pulsatile flow and arterial line filters, the levels of mean arterial pressure and flow to be maintained, and the use of agents such as prostacyclin during bypass surgery are all potentially important factors requiring evaluation.

We thank the consultant cardiothoracic surgeons Mr A Blesovsky, Mr A Hedley-Brown, $\mathrm{Mr} \mathrm{C} J$ Hilton, $\mathrm{Mr} M \mathrm{P}$ Holden, and $\mathrm{Mr} \mathrm{G} \mathrm{M}$ Morritt at Freeman Hospital, Newcastle upon Tyne, for allowing us to study the patients under their care; all the patients who so willingly agreed to take part in the study; and Ms B Niekirk for secretarial help. This study was supported by a grant to PJS from the British Heart Foundation.

\section{References}

1 Fox HM, Rizzo ND, Gifford S. Psychological observations of patients undergoing mitral surgery. Psychosom Med 1954;16:186-208.

2 Javid $H$, Tufo HM, Najafi $H$, Dye WS, Hunter JA, Julian OC. Neurological abnormalities following open-heart surgery. I Thorac Cardiovasc Surg 1969:58:502-9.

3 Sotaniemi KA. Brain damage and neurological outcome after open-heart surgery. I Neurol Neurosurg Psychiatry 1980;43:127-35.

4 Witoszka MM, Tamura H, Indeglia R, Hopkins RW, Simeone KA. Electroencephalographic changes and cerebral complications in open-heart surgery. F Thorac Cardiovasc Surg 1973;6: $855-64$

5 Aberg T, Kihlgren M. Effect of open-heart surgery on intellectual function. Scand $\mathcal{F}$ Thorac Cardiovasc Surg 1974; (Suppl 15):1-63.

6 Sotaniemi KA, Juolasmaa A, Hokkanen ET. Neuropsychologic outcome after open-hear surgery. Arch Neurol 1981;38:2-8.

Brierley JB. Neuropathological findings in patients dying after open-heart surgery. Thorax 1963;18:291-304

8 Patterson RH, Rosenfeld L, Porro R. Transient cerebral microvascular blockade after cardiopulmonary bypass. Thorax 1976;31:736-41.

9 Frank KA, Heller SS, Kornfeld DS, Malm JR. Long-term effects of open-heart surgery on intellectual functioning. I Thorac Cardiovasc Surg 1972;64:811-5.

10 Sachdev NS, Carter CC, Swank RL, Blachly PH. Relationship between post-cardiotomy delerium clinical neurological changes and EEG abnormalities. 7 Thorac Cardiovasc Surg 1967;54:557-63.

11 Aberg T, Kihlgren M. Cerebral protection during open-heart surgery. Thorax 1977;32:525-33.

12 Branthwaite MA. Prevention of neurological damage during open-heart surgery. Thorax 1975;30:258-61.

13 Favaloro RG. Saphenous vein autograft replacement of severe segmental coronary artery occlusion. Ann Thorac Surg 1968;5:334-9.

14 Consensus development conference: coronary artery bypass grafting. Br Med f 1984;289:1527-9.

15 Shaw PJ, Bates D, Cartlidge NEF, Julian DG, Shaw DA. Neurological and neuropsychological complications of coronary artery bypass graft surgery. $Q \mathcal{J}$ Med 1984;212:531-2.

16 European Coronary Surgery Study Group. Prospective randomised study of coronary artery bypass surgery in stable angina pectoris. Lancet 1980;ii:491-5.

17 Takaro T, Hultgren HN, Lipton MJ, Detre KM, et al. The VA cooperative randomised study of surgery for coronary arterial occlusion disease. II Subgroup with significant left main lesions. Circulation 1976;54(suppl 3);107-17.

18 English TAH, Bailey AR, Dark JF, Williams WG. The UK cardiac surgical register, 1977-82. Br Med f 1984;289:1205-8.

19 Aberg T, Ronquist G, Tyden H, et al. Adverse effects on the brain in cardiac operations as assessed by biochemical, psychometric and radiologic methods. I Thorac Cardiovasc Surg 1984;87: 99-105. 
20 Breuer AC, Furlan AJ, Hanson MR, et al. Neurologic complications of open heart surgery. Cleve $C$ lin $Q$ 1981;48:205-6.

21 Breuer AC, Furlan AJ, Hanson MR, et al. Central nervous system complications of coronary artery bypass graft surgery: prospective analysis of 421 patients. Stroke 1983;14:682-7.

22 Lederman RJ, Breuer AC, Hanson MR, et al. Peripheral nervous system complications of coronary artery bypass graft surgery. Ann Neurol 1982;12:297-301.

23 Lee MC, Geiger J, Nicoloff D, Klassen AC, Resch JA. Cerebrovascular complications associated with coronary artery bypass (CAB) procedure. Stroke 1979;10:107.

24 Gonzaáles-Scarano F, Hurtig H. Neurologic complications of coronary artery bypass grafting: case-control study. Neurology $(N Y)$ 1981;31:1032-5.

25 Martin WRW, Hashimoto SA. Stroke in coronary bypass surgery. Can f Neurol Sci 1982;9:21-6. 26 Bojar RM, Najafi H, Delaria GA, Serry C, Goldin MD. Neurological complications of coronary revascularisation. Ann Thorac surg 1983;36:427-32.

27 Coffey CE, Massey W, Roberts KB, Curtis S, Jones RH, Pryor DB. Natural history of cerebral complications of coronary artery bypass graft surgery. Neurology 1983;33:1416-21.

28 Sotaniemi KA. Cerebral outcome after extracorporeal circulation. Comparison between prospective and retrospective evaluations. Arch Neurol 1983;40:75-7.

29 Menkin M, Schwartzman RJ. Cerebral air embolism. Report of five cases and review of the literature. Arch Neurol 1977;34:168-70.

30 McKibbon DW, Bulkley BH, Green WR, Gott VL, Hutchins GM. Fatal cerebral atheromatous embolization after cardiopulmonary bypass. 7 Thorac Cardiovasc Surg 1976;71:741-5.

31 Breuer AC, Franco I, Marzewski D, Soto-Velasco J. Left ventricular thrombi seen by ventriculography are a significant risk factor for stroke in open-heart surgery. Ann Neurol 1981;10:103-4.

32 Caguin F, Carter MG. Fat embolism with cardiotomy with use of cardiopulmonary bypass. $\mathcal{f}$ Thorac cardiovasc Surg 1963;46:665-72.
33 Arfel G, Casanova C, Naquet R, Passelecq J, Dubost C. Etude électro-clinique de l'embolie gazeuse cérébrale en chirugie cardiaque. Electroencephalogr Clin Neurophysiol 1967;23:101-6.

34 Guidoin RG, Awad JA, Laperche Y, Morin PJ, Haggis GH. Nature of deposits in a tubular membrane oxygenator after prolonged extracorporeal circulation: a scanning electromicroscopy study. I Thorac Cardiovasc Surg 1975;69:479-91.

35 Hill JD, Aguilar MJ, Baranco A, de Lanerolle P, Gerbode F. Neuropathological manifestations of cardiac surgery. Ann Thorac Surg 1969;7:409-14.

36 Lindberg DAB, Lucas FV, Sheagren J, Malm JR. Silicone embolisation during clinical and experimental heart surgery employing a bubble oxygenator. Am f Pathol 1961;39:129-35.

37 De Paepe J, Pomerantzeff PMA, Nakiri K, Armeline E, Verginelli G, Zerbini EJ. Observation of the microcirculation of the cerebral cortex of dogs subjected to pulsatile and non-pulsatile flow during extracorporeal circulation. In: $A$ propos du debit pulse. Paris: Cobe Laboratories Inc, 1979.

38 Stockard JJ, Bickford RG, Schaube JF. Pressure dependent cerebral ischemia during cardiopulmonary bypass. Neurology (Minneap) 1973;23:521-9.

39 Hansen MR, Breuer AC, Furland AJ, et al. Mechanism and frequency of brachial plexus injury in open-heart surgery: a prospective analysis. Ann Thorac Surg 1983;36:675-9.

40 Vander Salm TJ, Cereda JM, Cutler BS. Brachial plexus injury following median sternotomy. $\mathcal{I}$ Thorac Cardiovasc Surg 1980;80:447-52.

41 Magee KR. Clinical analysis of reflexes. In: Vinken PJ, Bruyn GW, eds. Handbook of clinical neurology. Vol 1. Amsterdam: North Holland Publishing Co, 1969:237-56.

(Accepted 7 August 1985)

\section{Importance of early tumour exacerbation in patients treated with long acting analogues of gonadotrophin releasing hormone for advanced prostatic cancer}

We describe the transient stimulatory effect- "tumour flare"-that occurred in patients with locally advanced or metastatic symptomatic prostatic cancer who were treated with either buserelin (D-ser (TBU) ${ }^{6}$ LHRH ethylamide) or decapeptyl (D-(Trp) $)^{6}$ LHRH), agonist analogues of gonadotrophin releasing hormone.

\section{Patients, methods, and results}

Forty six men aged 52-82 with symptomatic locally advanced or metastatic prostatic cancer were treated. Five patients received buserelin $200 \mu \mathrm{g}$ thrice daily, 17 buserelin $200 \mu \mathrm{g}$ five times daily, and eight buserelin $400 \mu \mathrm{g}$ thrice daily intranasally, and five men were treated with monthly depot injections of buserelin calculated to release the compound at a mean rate of $150 \mu \mathrm{g}$ daily. Eleven patients received depot injections of decapeptyl, which released the drug at a mean rate of 50,100 , or $200 \mu \mathrm{g}$ daily over one month. Treatment was given for between one month and three years. All patients were assessed according to the criteria of the National Prostatic Cancer Project.

Objective improvement occurred in 26 of the 35 patients treated with buserelin and eight of the 11 patients treated with decapeptyl. Seventeen of 32 with bone pain at presentation and one without, however, had increased symptoms. Pain was generally first noted to have increased at 12 hours, became maximal at 36 hours, and eased by the end of the first treatment week. A patient with pelvic lymphadenopathy developed lymphoedema, which resolved after one week of treatment.

The 17 patients with increased bone pain experienced some additional problems. Four had increased lymphoedema, which was maximal at the end of the first treatment week and had resolved at one month. The serum creatinine concentration in one patient increased from 170 to $600 \mu \mathrm{mol} / \mathrm{l}(1.92$ to 6.79 $\mathrm{mg} / 100 \mathrm{ml}$ ) at the eighth treatment day and decreased at the end of the second treatment week.

The most serious case of tumour flare occurred in a patient presenting with bone pain and grade 4 weakness in the legs, who developed signs of compression of the cord with complete sphincter dysfunction and grade 3 weakness on the 13th treatment day. A pretreatment myelogram had shown indentation of the theca at lumbar disc spaces 1-4 while a myelogram on day 13 showed gross compression of the theca between the third and fifth lumbar vertebrae (figure). This patient had spinal radiotherapy and recovered full neurological function. Fourteen of the 19 patients with tumour flare responded to treatment.

\section{Comment}

Agonist analogues of gonadotrophin releasing hormone have provided an appreciable advance in the management of patients with advanced carcinoma of the prostate. ${ }^{1.3}$ They are equivalent in efficacy to conventional treatment for prostatic cancer ${ }^{4}$ but without its disadvantages. Because of the initial stimulatory effects of all agonists analogues, however, there may be a corresponding temporary increase in symptoms. Of the $46 \mathrm{men}$ in this series, 19 had increased symptoms. In two of this group renal and neurological function was severely compromised.

Labrie et al suggested that combined treatment with an antiandrogen and agonist analogues may improve the response and its duration and avoid tumour flare. ${ }^{5}$ We have described the incidence and potential importance of the initial stimulatory effects of agonist analogues. These observations do not minimise the contribution of the gonadotrophin releasing hormone
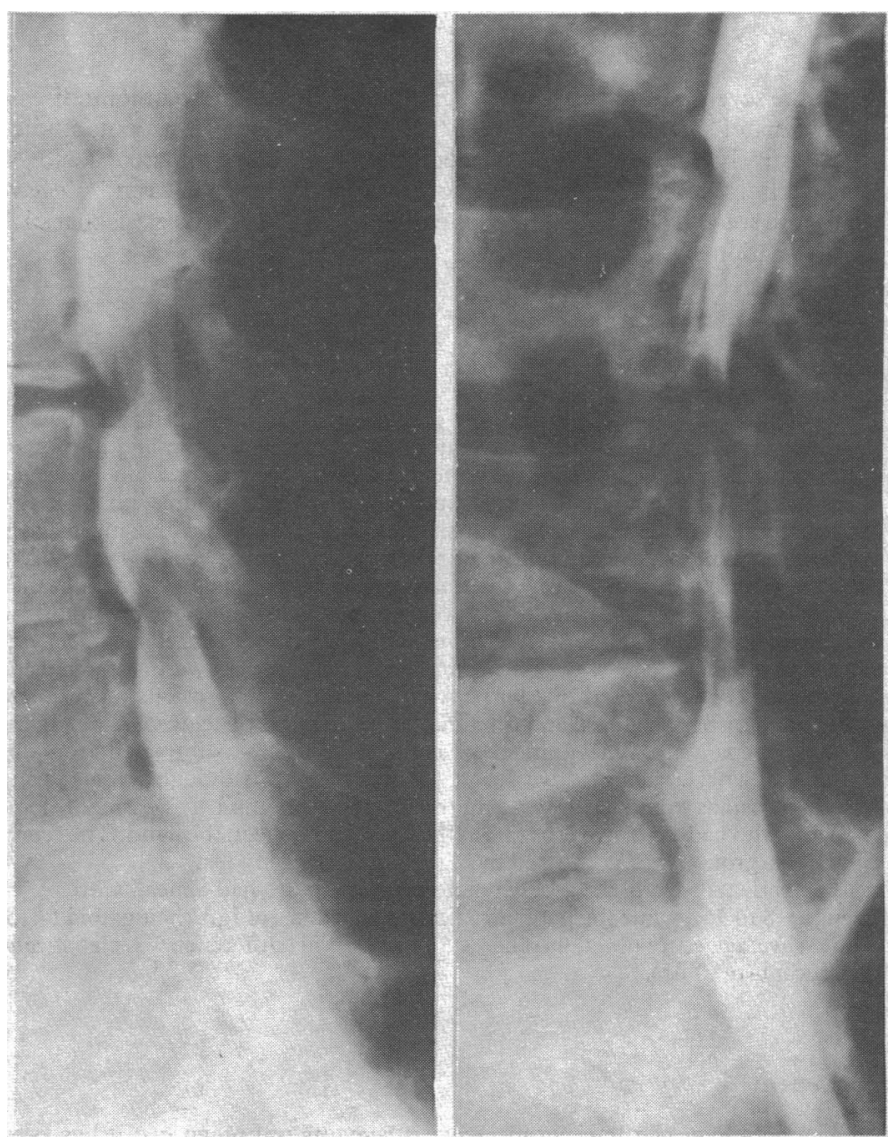

Changes in myelogram in patient with tumour flare in lumbar region. Left: Before treatment. Right: On day 13 of treatment. 